\title{
Walter Riss, PhD, 1925-2015
}

We are saddened to note the passing of Walter Riss on May 24, 2015. Walter grew up in New Britain, Conn., USA, and received his undergraduate and postgraduate education at the Universities of Connecticut, Rochester and Kansas, where he trained in physiological psychology and neuroanatomy. He was Professor of Neuroscience and the former Director of the Biological Psychology Graduate Program at the SUNY Downstate Medical Center. Walter was the founder and first Editor-in-Chief of Brain, Behavior and Evolution. The purpose of this journal is to integrate knowledge about the anatomy and physiology of the nervous system with knowledge about its evolution and the evolution of behavior.

During his graduate and postdoctoral training, Walter studied the neural mechanisms of sound localization and reproductive physiology. In his early years as Assistant Professor at Downstate, he continued research on the neural and behavioral influences on endocrine development and function. Perhaps excited by the introduction of the new silver-staining methods for tract tracing, which provided a more secure platform for research on comparative neuroanatomy, Walter turned his interest toward the evolution of the nervous system. His early contributions to his new field of endeavor included studies on the amphibian and reptilian visual system and the cytoarchitecture of the reptilian forebrain. In addition, he wrote a number of theoretical papers intended to model the progression of neural circuits from simpler to more complex life forms.

Walter was a dynamic and forward-thinking entrepreneur. In initiating the Biological Psychology Program, he established the first interdisciplinary graduate program at Downstate. He was instrumental in promoting or organizing a number of symposia at the New York Academy of Sciences to promote interest in neural evolution, at the Massachusetts Institute of Technology on the subcortical visual system and at Downstate on basic thalamic structure and function. Papers from the last two symposia were published in special issues of Brain, Behavior and Evolution. It is not surprising that Walter inspired and mentored a group of young trainees, ourselves included, to begin careers in vertebrate evolutionary neuroscience. Thinking back on those days with nostalgia, the labs were filled with tanks of frogs, salamanders, turtles, snakes and alligators, some of which caused a commotion when they escaped into the hallway.

He will also be remembered for his wit and keen mind, for his skill in the teaching of neuroanatomy and for his role as a model teacher for those of us who worked with him at Downstate. The role of a professor, according to Walter, is to increase knowledge through research, to make knowledge comprehensible to students so that they may carry on investigative and educational efforts and to transmit to them 'some sense of the enthusiasm' that the teacher has for his subject matter. He mentored a number of students and fellows including Frank Scalia, Kalman Rubinson, Robert Peterson, Robert Knobler and Elliott Mufson. Perhaps the most characteristic feature of Walter was his corncob pipe, which he smoked all the time. One had to blow away the haze of the smoke to find Walter hidden in his small office. He would often pause in mid-sentence for a long draw on his pipe, but he always 
resumed with a perfectly cogent and grammatically correct conclusion. His droll sense of humor was always on display.

We all feel a deep sorrow at Walter's passing. At the same time, we are thankful that we were able to have him as a mentor and could work together with him for several years at Downstate Medical Center. I am sure all the people who worked with Walter share these feelings. His students and fellows will always remember him as a devoted scientist and an exceptional teacher. He lived his professional and personal life to the fullest, creating a path for others while making his own highly significant contributions to the field of neuroscience.

Walter, a WWII veteran, was the beloved husband of Barbara, father of Richard, Elizabeth LaRose, Joan Riss and Charles, grandfather of Christopher, Timothy and Jonathon LaRose and great-grandfather of Isabelle LaRose.

He will be missed!

Elliott Mufson, Kalman Rubinson, Frank Scalia 